\title{
Neonatal Mortality in the Neonatal Intensive Care Unit at Benghazi Pediatric Hospital- Libya
}

\author{
Zahra Mansour Alharam, Isaada Ali Abdalla Elsaeti* and Mohamed Masoud Alferjani
}

${ }^{2}$ Department of Pediatrics, Faculty of Medicine, University of Benghazi - Libya

Received: 15 November 2020 / Accepted: 30 December 2020

Doi: https://doi.org/10.54172/mjsc.v35i4.331

\begin{abstract}
This research aims to study mortality rates and identify the direct causes of neonatal deaths among newborns at Benghazi Pediatric Hospital. A descriptive case series study was conducted during 2015. Data included; birth weight, gender, residency, duration of hospital stay, age of neonates at death, and causes of death. Out of 1610 neonatal admissions reviewed, the total number of deaths was 122 during 2015. The data focused on death certificates of neonates and showed that the male gender was predominant (62.3\%). Most of them had a birth weight ranged between 2-2.9 $\mathrm{Kg}$. Approximately $52 \%$ of neonatal deaths in one day were of newborns $<1$ week old, and $54 \%$ were full-term newborns. The most frequent direct single cause of death in neonates was prematurity, then neonatal sepsis and congenital heart disease respectively. The study concluded that the most frequent causes of infant mortality related deaths were prematurity then neonatal sepsis. Furthermore, future research is recommended, and the calculation of early and late neonatal mortality rate with the availability of total live births.
\end{abstract}

Keywords: Neonate, mortality, causes.

\section{INTRODUCTION}

The neonatal period (an infant in the first 28 days after birth) is a highly vulnerable period of life when a neonate may develop certain serious problems which lead to death (Babaei \& Dehghan, 2018; Kumar, Mundhra, Jain, \& Jain, 2019; Weldearegawi et al., 2015). Neonatal mortality is highest in the first 24 hours of life and accounts for $65 \%$ of infant mortality (Babaei \& Dehghan, 2018). The neonatal mortality rate is the number of neonates dying before reaching 28 days of age, per 1,000 live births in a given year (Babaei \& Dehghan, 2018; Kalita, Kalita, Dutta, \& Sharma, 2019). A World Health Organization (WHO) report stated that worldwide neonatal mortality rates decreased from 36 deaths per 1,000 live births in 1990 to 19 cases per 1,000 live births in 2015, which indicates that the neonatal mortality rate has fallen by 45 to $47 \%$ during these years. Whereas according to the latest statistics released by the United
Nations Children's Fund (UNICEF), 2.6 million children died in the first month of life in 2016 - approximately 7,000 newborn deaths every day - most of which occurred in the first week, with about 1 million dying on the first day and close to 1 million dying within the next six days(Kliegman, 2016). For every baby who dies in the first week after birth, another is born dead (fetal deaths or stillbirths). Causes and determinants of neonatal deaths and stillbirths differ from those causing and contributing to post-neonatal and child deaths. Neonatal deaths and stillbirths stem from poor maternal health, inadequate care during pregnancy, poor management of complications during pregnancy and delivery, poor hygiene during delivery and the first critical hours after birth, and lack of newborn care. Health workers at the primary and secondary level of care often lack the skills to meet the needs of newborn infants, since the recognition of opportunity is only just emerging globally, and their experience in this area is therefore limited. Over the 
last two decades, infant and child survival has remained a top global priority. 7.6 million children die each year from preventable causes worldwide, and of these, about $40 \%$ die in the neonatal period (Aleshina \& Redmond, 2005; Bairoliya \& Fink, 2018). The majority of the neonatal deaths took place in impoverished countries where the neonatal care standard is below the desired level. Under-five mortality is declining at a rate of around three percent, yet the reduction in the neonatal mortality rate $(2.1 \%$ per year $)$ lags behind the rate of reduction among older ages. As infant mortality is the most sensitive indicator of population health, a high infant mortality rate (IMR) reflects the presence of unfavorable social, economic, and environmental conditions during the first year of life (Kumar et al., 2019; Weldearegawi et al., 2015).

Furthermore, the neonatal outcome is an important indicator of obstetrics and health care, as it has a significant role in providing the information needed to improve the health status of pregnant women, and newborns (Babaei \& Dehghan, 2018). Five leading causes of infant death: the United States, 2010-2017 were congenital malformations, short gestation, low birth weight, maternal complications of pregnancy, sudden infant death syndrome, and accidents (unintentional injuries) (Ely \& Driscoll, 2019; He, Akil, Aker, Hwang, \& Ahmad, 2015)Globally, the leading causes of death are estimated to be preterm birth (28\%), severe infections (26\%), asphyxia $(23 \%)$, and congenital anomalies $(7 \%)$.

Advances in perinatal and neonatal care have significantly reduced neonatal mortality rates and have benefited preterm infants admitted to neonatal intensive care units (NICU) in the last decades. The survival and health of newborn babies are a critical part of the push towards lower child mortality in the Millennium Development Goal 4 and 5. The aim of the United Nations' Millennium Development Goal (MDG4 and MDG5) is to reduce newborn mor- tality in every country to 12 or fewer deaths per 1,000 live births, and to reduce under-five mortality in every country to 25 or fewer deaths per 1,000 live births ${ }^{(11)}$. The neonatal outcome is an important indicator of obstetrics and health care. It has a significate role in providing the information needed to improve the health status of pregnant women, and newborns ${ }^{(11) .}$ Neonatal mortality rate (NMR) differs from the perinatal mortality rate in that it focuses only on deaths among live births and covers an extended period after birth. Early neonatal deaths (neonatal deaths in the first week of life) are more closely associated with pregnancy-related factors and maternal health, whereas late neonatal deaths (neonatal deaths $7-28^{\text {th }}$ day of life) are associated more with factors in the newborn's environment.

\section{Common causes of neonatal mortality}

1. Prematurity: Premature infants come early into the world, and they are born fragile, small, and weighing less than full term infants. Many of the babies who survive face greater risks of significant health problems and disability throughout their lives (I.e. learning disabilities, visual and hearing problems, chronic lung disease and other long-term diseases).

2. Neonatal infections: Neonatal infections are a major cause of death worldwide. It is estimated that approximately 4 million deaths occur annually in developing countries in the neonatal period.

3. Birth Asphyxia: It is estimated that in developing countries, asphyxia causes around seven deaths per 1000 births, whereas in developed countries, this proportion is less than one death per 1000 births .

4. Respiratory Distress Syndrome (RDS) or Hyaline Membrane Disease (HMD): RDS is one of the most common causes of neonatal respiratory failure. According to the National Neonatal Perinatal Database 2003, HMD was found to affect $1.2 \%$ of total live births and contributed to $13.5 \%$ of total neonatal deaths. 
5. Congenital anomalies: Congenital malformation such as congenital heart diseases and metabolic disorders are common causes of infant mortality.

As birth and death are the two most important events in life, any person has legal existence between the recorded timings of those two events. In addition to the legal importance of recording births and deaths, there is importance relevant to vital basic data about the population group. Any planned activity in concern to the population, including health care needs, such statistical information collected from the registration of births and deaths. Also, the magnitude of specific diseases can be assessed using registered deaths relevant to diseases listed in medical certifications of death. This makes the registration of deaths of paramount importance epidemiologically (Kotabagi, Chaturvedi, \& Banerjee, 2004). In an effort to reduce infant and child mortality, massive investment has been made to improve access to health-care, nutrition, hygiene and sanitation, and promote exclusive breastfeeding. As a result, world regions have shown reductions in IMR and underfive mortality rates. However, these achievements are challenged by disparities that persist among regions and within countries (Kumar et al., 2019). Therefore, this paper aimed to study mortality in newborns and identify the direct causes of neonatal deaths to achieve the goal of reducing neonatal deaths via policy efforts to promote infant health and under-five children in Benghazi Libya.

Objectives of the study: To study mortality and identify the direct causes of neonatal deaths among newborn babies.

\section{MATERIALS AND METHOD}

\section{Design, sample size, and settings of the} study: A descriptive case series hospitalbased study was conducted from registration files in the neonatal intensive care unit and death certificates in the statistical department in Benghazi Pediatric Hospital.

Study duration and variables of the study: The study was conducted during the period between January and December 2015. Out of 1610 newborn babies admitted to neonatal intensive care in Benghazi Pediatric Hospital in the year (2015), the total number of deaths was 122 . The study's focus was on death certificates. Variables studied include the following; birth weight, gender, residency, date of hospital admission, duration of stay in the hospital, age of neonates at death, and causes of death.

Ethical Considerations: Verbal consent was taken from the head of the Intensive Care Unit and the head of the Statistical Department at Benghazi Pediatric Hospital (Teaching Hospital). Confidentiality of data was guaranteed.

Statistical methods: Statistical analysis of study results was performed by the application of the statistical package social science software version 17 (SPSS). Data was collected, analyzed, and expressed as frequency distributions and then computed in percentages in tables and figures. Simple descriptive statistical parameters such as ratio, mean, standard deviation, minimum, and maximum were done. For categorical variables, a chisquare test was applied to test for association. A P-value of less than 0.05 was considered statistically significant in all statistical analyses.

\section{RESULTS}

Out of 1610 neonatal admissions reviewed, the total number of deaths at Benghazi Pediatric Hospital was 122 (7.5\%) of total neonatal admissions to the hospital during the year 2015. The male and female represent $62.3 \%$ and $37.7 \%$ respectively. The male to female ratio $\mathrm{M}: \mathrm{F}=1.7: 1$. The vast majority of neonatal mortality cases $91.8 \%$, were residing in Benghazi, whereas the minority $8.2 \%$, were from outside Benghazi. 
The minimum birth weight of neonate mortality was $0.7 \mathrm{mg}$, and the maximum was $4.7 \mathrm{~kg}$. Whereas the mean birth weight was 2.63 and the standard deviation of birth weight 0.821 . Neonatal mortality according to hospital stay was classified into four categories as following: Stay at the hospital from $0-1$ week $(78 \%)$, more than 1 week - 2 weeks (13.1\%), more than 2 weeks -3 weeks $(2.6 \%)$ and stay at the hospital more than 3 weeks was $(6.1 \%)$. Regarding the distribution of newborn mortality according to maturity, there were full-term case in more than half of newborns $(54.1 \%),(21.3 \%)$ were preterm, and data was missing in $(24.5 \%)$ of newborn mortality cases.

Table (1): Descriptive statistic birth weight of neonate mortality in the Neonatal Intensive Care $\underline{\text { Unit at }}$ Benghazi Pediatric Hospital.

\begin{tabular}{lll}
\hline \multicolumn{1}{r}{ Birth weight } & \multicolumn{1}{c}{ Number } & \multicolumn{1}{c}{$\%$} \\
\hline $0.7-0.9 \mathrm{mg}$ & 2 & 1.6 \\
$1-1.9 \mathrm{~kg}$ & 21 & 17.2 \\
$2-2.9 \mathrm{~kg}$ & 42 & 34.4 \\
$3-3.9 \mathrm{~kg}$ & 32 & 26.2 \\
$4 \mathrm{~kg}$ or more & 5 & 4.0 \\
Missed & 20 & 16.4 \\
Total & 102 & 100 \\
\hline \hline
\end{tabular}

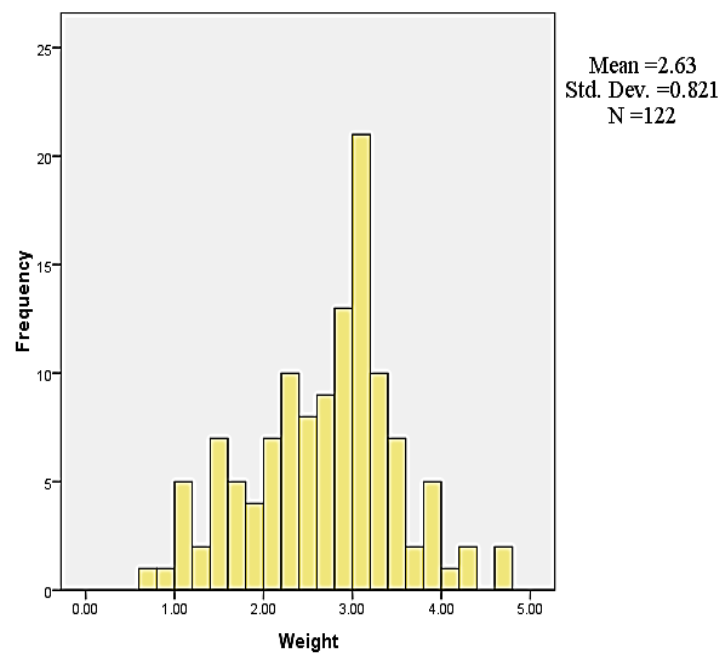

Figure (1): Distribution of mortality among newborn babies according to birth weight.
Table (2): Distribution of age of neonate mortality at Benghazi Pediatric Hospital.

\begin{tabular}{llll}
\hline \hline $\begin{array}{c}\text { Characteris- } \\
\text { tics/Parameters }\end{array}$ & Details of age & No. & $\%$ \\
\hline \multirow{3}{*}{$\begin{array}{llll}\text { Death according } \\
\text { to age }\end{array}$} & One day- $<1$ week & 63 & $51.6 \%$ \\
& 2week- $<2$ weeks & 20 & $16.39 \%$ \\
& 3weeks-1month & 19 & $15.57 \%$ \\
\hline \hline
\end{tabular}

Table (3): The causes of admission of newborns to Benghazi Pediatric Hospital.

\begin{tabular}{llll}
\hline \hline & $\begin{array}{l}\text { Diagnosis at admis- } \\
\text { sion }\end{array}$ & Frequency & $\%$ \\
& Jaundice & 550 & 34.16 \\
& $\begin{array}{l}\text { Neonatal sepsis } \\
\text { Respiratory diseas- }\end{array}$ & 240 & 14.9 \\
& es & 14.5 \\
& Prematurity (Birth & 263 & \\
& weight < 2.4 Kg & & 16.3 \\
Admission & Convulsion & 77 & \\
Causes & Congenital heart & 52 & 4.8 \\
& $\begin{array}{l}\text { diseases } \\
\text { Multiple congeni- }\end{array}$ & 38 & \\
& tal anomaly & & 2.4 \\
& Birth asphyxia & 25 & 1.6 \\
& $\begin{array}{l}\text { Meningitis } \\
\text { Insulin dependent }\end{array}$ & 41 & 2.5 \\
diabetes & & 2.2 \\
Others & 45 & 2.8 \\
Total admissions & 1610 & 100 \\
\hline \hline
\end{tabular}

The above table shows the diseases or morbid conditions which either resulted in a direct cause of death or contributed to death.

Table (4): Causes of death of newborns.

\begin{tabular}{lll}
\hline \hline Causes of death & Number & $\%$ \\
\hline Congenital heart diseases & 16 & 13.11 \\
Neonatal sepsis & 23 & 18.85 \\
Respiratory disorders* (respirato- & 27 & 22.13 \\
ry distress syndrome, pneumotho- & & \\
rax, aspiration pneumonia) & & \\
Prematurity & 32 & 26.23 \\
Multiple congenital anomaly & 14 & 11.48 \\
Birth asphyxia & 4 & 3.30 \\
Metabolic disorders & 2 & 1.64 \\
Renal impairment & 1 & 0.82 \\
Bleeding disorders & 1 & 0.82 \\
Necrotizing enterocolitis (NEC) & 2 & 1.64 \\
Total & 122 & $100 \%$ \\
\hline \hline
\end{tabular}


Among respiratory disorders, there were (Respiratory distress syndrome in fifteen neonates, six neonates had Pneumothorax, Brnchopneumia \& Aspiration pneumonia in five \& one neonate had Muconium aspiration). The other causes that contributed to death included one case of dehydration, one case of intestinal obstruction, two cases died due to disseminated intravascular coagulation, and two had Neuroblastoma. Multiple causes of death and cardiopulmonary arrest were mentioned on $37(30 \%)$ death certificates of newborns.

Table (6): Cross-tabulation of neonatal sepsis and congenital heart diseases' related mortality distribution according to gender.

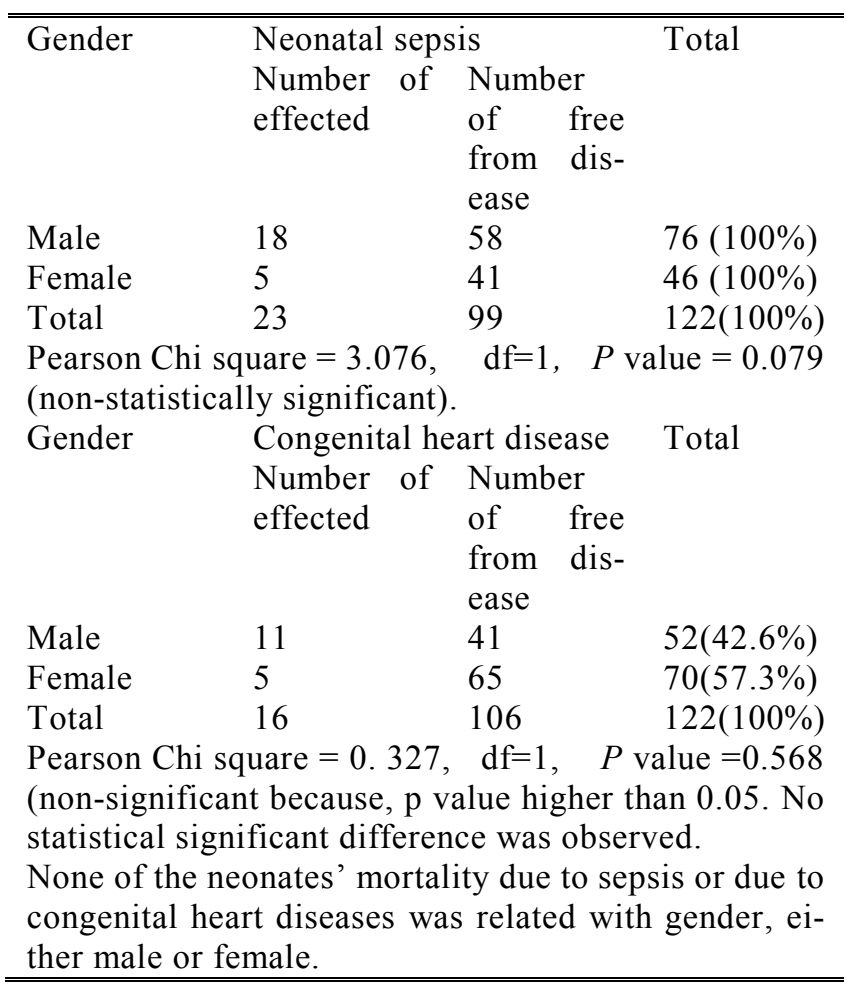

\section{DISSCUSSION}

Out of 1610 neonatal admissions to the Benghazi Children Hospital during 2015, there were 122 neonatal deaths $(7.5 \%)$. The remaining $1488(92.4 \%)$ neonates were discharged after improvement. In this study, the male gender was predominant. Nearly $52 \%$ occurred in the first week of life (early neo- natal death at one day $-<1$ week). These results are similar to the data reported by Fituri et al. 2014-2016, which recorded 28930 newborn babies admitted to the neonatal intensive care unit. In the Tripoli medical center, reported neonatal deaths were at $3.2 \%$, and the neonatal mortality rate (NMR) calculated was $10.1 / 1000$, where 250 of the babies died in the neonatal period, and 38 babies died in the post-neonatal period. $65.3 \%$ of the neonatal deaths occurred in the first week of life, while $21.5 \%$ died in the late neonatal period (Sherlala, Sabei, \& Fituri, 2017). Likewise, a study conducted by Minyahil (2014) showed that most neonatal deaths occur in the $1^{\text {st }}$ week of life (Woldu et al., 2014).

In this study, more than half of the deaths were full-term babies (54\%). Most of them had a birth weight ranged between $2-2.9 \mathrm{Kg}$ and 3-3.9 Kg. A limited number of babies were below $2.5 \mathrm{Kg}$. Regarding the maturity of newborns with neonatal deaths, a fair amount of data was missing, nearly $25 \%$ of the sample size (not written in the medical records whether the babies were delivered full-term or premature). This makes an error in the findings that affects the results. The neonatal deaths in full-term babies with normal weight in this study were explained based on missing data, and these results were inconsistent with the literature.

The present study demonstrated that the vast majority of the neonates died in the first week of life compared with other studies (Bashir M. et al. 2018; Gebremedhin, Berhe, \& Gebrekirstos, 2016; Warren \& Anderson, 2009)

The common causes of admission to the ICU at Benghazi Children Hospital were Jaundice followed by prematurity. Whereas Rakesh's study in 2019 revealed that neonatal jaundice, birth asphyxia, and sepsis are the most common causes of admission (Kumar et al., 2019). Another study conducted by Homa and his colleagues in Kermanshah in Iran (C) 2020 The Author(s). This open access article is distributed under a CC BY-NC 4.0 license. ISSN: online 2617-2186 print 2617-2178 
2014-2016 found that understanding the causes of death in neonatal intensive care units and the modifiable factors associated with death could possibly reduce infant mortality. It is necessary to identify the causes of mortality in each country or country regions in order to minimize it. The study also demonstrated that the most common causes of neonatal death were prematurity (gestational age below 37 weeks), and its related complications, for example, respiratory distress syndrome and sepsis. The highest death rate occurred in the first week of birth and during the night shift. Also, the highest number of infant deaths was of boys, and lowest number was of those resuscitated in the delivery room. Considering the high prevalence of neonatal mortality with lower gestational age, more care in preventing preterm delivery, as the most important cause of neonatal mortality, can be of particular importance in reducing neonatal mortality (Babaei \& Dehghan, 2018).

Another similar study in Misurata - Libya reported that the infant mortality rate and neonatal mortality rate, which plays an important role in health planning and neonatal outcome, is a major indicator of obstetrics and health care, where it has an important role in providing the information needed to improve the health status of pregnant women and newborns (Bashir et al. 2014).

The missed data can lead to errors in the results.(Angus, Linde-Zwirble, Clermont, Griffin, \& Clark, 2001). The study findings indicated that the most frequent direct single cause of death in neonates was prematurity $(26.2 \%)$, then neonatal sepsis, and congenital heart disease $(18.8 \%$ and $13.1 \%)$ respectively. Also, a multiple congenital anomaly was on $(11.4 \%)$ of death certificates and cardiopulmonary arrest was mentioned on 37 of the death certificates of newborns.

Another study in Egypt in 2000 showed that prematurity was the primary cause of death in
Egyptian neonates, while the WHO estimates gave infections, including tetanus, as the main cause (Campbell et al., 2004).

A retrospective study was conducted by Dulal et al. in Tezpur- India the finding were a decreasing trend of neonatal mortality rates (NMR) in Tezpur. Birth asphyxia, low birth weight, and sepsis are the leading causes of neonatal mortality. This neonatal mortality can be brought down by providing adequate antenatal care, improving maternal nutritional status, close monitoring of fetal wellbeing in pregnancy, the timely intervention of delivery, good neonatal resuscitation care, and early referral of sick newborns to neonatal intensive care units (Kalita et al., 2019).

While, a study in Jimma-Ethiopia also represented the major factors that affect the survival time of preterm were prenatal Asphyxia, Sepsis, Hyaline membrane disease, jaundice, gestational age, temperature, and respiratory distress syndrome for time to death of premature infants. Furthermore, a previous study found the same findings (Wang et al., 2013; Wesenu, Kulkarni, \& Tilahun, 2017). A previous study reported that with advances in diagnostic and treatment modalities as well as government initiatives to decrease neonatal mortality, significant achievements have been made. Common causes of mortality were birth asphyxia, sepsis, and prematurity (Kumar et al., 2019).

Furthermore, (Jain et al., 2019) performed a study that reported that the causes of neonatal deaths were prematurity-related complications followed by intrapartum-related events. Birth asphyxia and sepsis accounted for most neonatal deaths, $80 \%$ of which are preventable with simple interventions. Understanding the cause and timing of neonatal deaths is critical for forming public health policies targeted at reduce the neonatal mortality rate (Jain et al., 2019).

Whereas a Tripoli-Libya study recorded that prematurity and its complications were the 
main cause of death (Sherlala et al., 2017). Similarly, deaths due to respiratory distress syndrome were common in preterm and male neonates (Iyer, Naveen, Suma, Kumarguru, \& Sweta, 2018). Finally, a study in Indonesia found that hyaline membrane disease, neonatal infection, and prematurity are responsible for high morbidity and mortality rates among neonates (Sastroasmoro, 1998). In addition, the current study showed that the M:F ratio was $1.7: 1$. However, the association between congenital heart disease, neonatal sepsis, and gender in deceased newborns was insignificant (No statistically significant difference was observed). The common cause of neonatal admission to Benghazi Pediatric Hospital was Jaundice, followed by respiratory disorders and neonatal sepsis. These findings are in agreement with the respiratory disorders reported in literature, as neonatal sepsis is the most frequent cause of admission for neonatal intensive care in both term and preterm (Ezeh, 2017; Goldenberg, Culhane, Iams, \& Romero, 2008; Kliegman, 2016; Moise, 2018 ; Amorim, et al, 2018).

Limitation of the study: The data collected in this study only reflected a percentage of Benghazi Pediatric Hospital cases and not all cities in the country. The results may lack generalizability due to the short period of time at which the study was conducted. Important missing information not recorded in medical records was significant in some variables such as mothers' age, parity, and maternal complications. Also important data for the neonates were missing such as birth weight and maturity. Therefore, lack of information on the death certificates creates errors. Unfortunately, with regard to the total live births in 2015, no data was collected due to legal issues. Consequently, the neonatal mortality rate could not be calculated.

\section{CONCLUSION}

Based on the current study's results, the male gender was predominant. The vast majority of neonatal mortalities were admitted to the Hospital from Benghazi city. Most newborns had a normal delivery. Few newborns were delivered by caesarean section. There were 122 neonatal deaths, where nearly half of them died before the first week, which is a warning sign for health services. Most newborns stay in hospital from one to ten days. Also, the current study concluded that the most frequent causes of neonatal-related deaths were prematurity, then neonatal sepsis, and congenital heart disease. Also, multiple congenital anomalies were recorded on death certificates. In addition, among multiple causes of death, cardiopulmonary arrest was mentioned on newborns' death certificates.

\section{REFERENCES}

Aleshina, N., \& Redmond, G. (2005). How high is infant mortality in Central and Eastern Europe and the Commonwealth of Independent States? Population studies, 59(1), 39-54.

Angus, D. C., Linde-Zwirble, W. T., Clermont, G., Griffin, M. F., \& Clark, R. H. .(2001)Epidemiology of neonatal respiratory failure in the United States: projections from California and New York. American journal of respiratory and critical care medicine, 164(7), 1154-1160.

Amorim Melo ERA, de Barros Lima Filho A, Furtado Ferreira AC, de Sousa Carvalho G, da Conceição Brito JJ, (2018). Prevalence of Meningitis in Patients with Late Neonatal Sepsis in a Reference Maternity. Ann Pediatr Child Health. 6 ( 3): 1148.

Babaei, H., \& Dehghan, M. (2018). Study of causes of neonatal mortality and its related factors in the neonatal intensive care unit of Imam Reza hospital in Kermanshah, Iran during (2014-2016). 
International Journal of Pediatrics, 6(5), 7641-7649.

Bairoliya, N., \& Fink, G. (2018). Causes of death and infant mortality rates among full-term births in the United States between 2010 and 2012: An observational study. PLoS medicine, 15(3), e1002531.

Bashir M. Ashour, Anwar Gassier, Yosef Shami, Jalal A. Bilal \& Ishag Adam. (2014). Neonatal outcome in Misurata central Hospital - Libya. Journal of Science. 4 (2) :87-89.

Campbell, O., Gipson, R., El Mohandes, A., Issa, A. H., Matta, N., Mansour, E., \& Mohsen, L. (2004). The Egypt national perinatal/neonatal mortality study 2000 . Journal of Perinatology, 24(5), 284289.

Ely, D. M., \& Driscoll, A. K. (2019). Infant mortality in the United States, 2017: data from the period linked birth/infant death file.

Ezeh, O. K. (2017). Trends and populationattributable risk estimates for predictors of early neonatal mortality in Nigeria, 2003-2013: a cross-sectional analysis. BMJ open, 7(5), e013350.

Gebremedhin, D., Berhe, H., \& Gebrekirstos, K. (2016). Risk factors for neonatal sepsis in public hospitals of Mekelle City, North Ethiopia, 2015: unmatched case control study. PloS one, 11(5), e0154798.

Goldenberg, R. L., Culhane, J. F., Iams, J. D., \& Romero, R. (2008). Epidemiology and causes of preterm birth. The lancet, 371(9606), 75-84.

He, X. ‘Akil, L., Aker, W. G., Hwang, H.-M., \& Ahmad, H. A. (2015). Trends in infant mortality in United States: A brief study of the southeastern states from 2005-2009. International journal of environmental research and public health, 12(5), 4908-4920.

Iyer, C., Naveen, G., Suma, H., Kumarguru, B., \& Sweta, K. (2018). Janakiraman. Clinical profile and outcome of neonates with suspected sepsis form a rural medical college hospital of South India. Int J Contemp Pediatr, 5, 55-60.

Jain, K., Sankar, M. J., Nangia, S., Ballambattu, V. B., Sundaram, V., Ramji, S., . . Sivanandan, S. (2019). Causes of death in preterm neonates $(<$ 33 weeks) born in tertiary care hospitals in India: analysis of three large prospective multicentric cohorts. Journal of Perinatology, .19-13، (1)39

Kalita, D., Kalita, P., Dutta, A., \& Sharma, B. (2019). Morbidity and Mortality profile of newborns admitted to the neonatal intensive care unit of a tertiary care hospital, Assam, India.

Kliegman, R. M. (2016). Respiratory distress syndrome. Nelson Textbook of Pediatrics. 20th edition. Elsevier.

Kotabagi, R., Chaturvedi, R., \& Banerjee, A. (2004). Medical certification of cause of death. Medical Journal Armed Forces India, 60(3), 261-272.

Kumar, R., Mundhra, R., Jain, A., \& Jain, S. (2.).019Morbidity and mortality profile of neonates admitted in special newborn care unit of a teaching hospital in Uttarakhand, India.

Moise, I. K. (2018). Causes of Morbidity and Mortality among Neonates and Children in Post-Conflict Burundi: A Cross-Sectional Retrospective Study. Children, 5(9), 125. 
Sastroasmoro, S. (1998). Risk Factors for the Development of Hyaline Membrane Disease in Preterm Infants. Paediatrica Indonesiana, 38(11-12), 243-254.

Sherlala, N., Sabei, L., \& Fituri, N. (2017). Analysis of neonatal mortality at $\mathrm{Al}$ Jala Maternity and Gynecology Hospital Neonatal Intensive Care Unit (Tripoli, Libya 2014-2016).

Wang, K., Bhandari, V., Chepustanova, S., Huber, G., Stephen, O., Corey, S., . . . Kirby, M. (2013). Which biomarkers reveal neonatal sepsis? PloS one, 8(12), e82700.

Warren, J. B., \& Anderson, J. M. (2009). Core concepts: respiratory distress syndrome. NeoReviews, 10(7), e351-e361.

Weldearegawi, B., Melaku, Y. A., Abera, S. F., Ashebir, Y., Haile, F., Mulugeta, A., . . . Spigt, M. (2015). Infant mortality and causes of infant deaths in rural Ethiopia: a population-based cohort of 3684 births. BMC public health, 15(1), $1-7$.

Wesenu, M., Kulkarni, S., \& Tilahun, T. (2017). Modeling determinants of timeto-death in premature infants admitted to neonatal intensive care unit in Jimma University Specialized Hospital. Annals of Data Science, 4(3), 361-381.

Woldu, M. A., Guta, M. B., Lenjisa, J. L., Tegegne, G. T., Tesafye, G., \& Dinsa, H. (2014). Assessment of the incidence of neonatal sepsis, its risk factors, antimicrobials use and clinical outcomes in Bishoftu General Hospital, neonatal intensive care unit, DebrezeitEthiopia. Int $J$ Contemp Pediatrics, 1(3), 135-141. 


\section{وفيات الأطفال حديثي الولادة في وحدة العناية المركزة لحديثي الولادة \\ بمستشفى بنغازي للأطفال - ليبيا.}

زهرة منصور ، سعيدة علي عبد الله" ومحمد مسعود الفرجاني

قسم الأطفال، كلية الطب البشري، جامعة بنغازي - بنغازي

تاريخ الاستلام: 15 نوفمبر 2020/ تاريخ القبول: 30 ديسمبر 2020 https://doi.org/10.54172/mjsc.v35i4.331:Doi

المستخلص: يهدف البحث إلى دراسة معدلات الوفيات، وتحديد الأسباب المباشرة لوفيات الأطفال حديثي الولادة في مستشفى

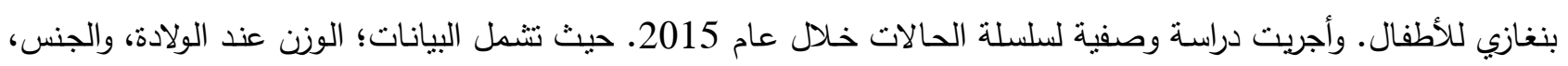
والإقامة، ومدة الإقامة في المستشفى، وعمر حديثي الولادة عند الوفاة، وأسباب الوفاة. من أصل 1610 حالة تم دراسه مراجعتها لحديثي

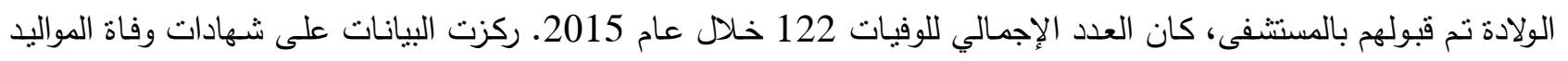
وأظهرت أن الذكور هم الغالب (62.3\%). تراوح وزن معظمهم عند الولادة بين 2 - 2.9 كجم. ما يقارب من 52\% كن كن وفيات المواليد في يوم واحد كانت لحديثي الولادة أعمارهم أقل من أسبوع، و 54٪ أطفال مكتملو المدة. كان السبب الوحيد المباشر الأكثر شيوعًا للوفاة عند الأطفال حديثي الولادة هو الإنتان الخداجي، ثم الإنتان الوليدي (التهابات المواليد)، ثم أمراض القلب التب

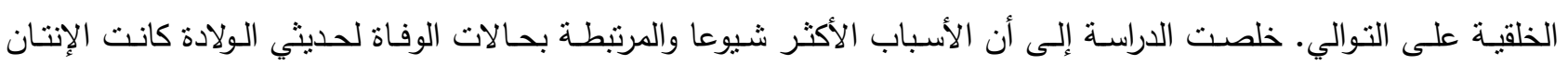
الخداجي، ثم الإنتان الوليدي. كذللك توصى بالبحوث المستقلية وحساب معدل وفيات المواليد المبكرة والمتأخرة مع نوفر إجمالي المواليد الأحياء. الكلمات المفتاحية: حديثو الولادة، الوفيات، المسببات. 